\title{
Nah Doongh's Song: Grace Karskens and Mark McKenna in conversation
}

\author{
Grace Karskens and Mark McKenna
}

\begin{abstract}
Grace Karskens's biographical essay 'Nah Doongh's Song' tells the story of an Aboriginal woman from Mooro Morack, Penrith. In 2019 the essay won the Australian Book Review's Calibre Prize, and in June that year Grace and historian Mark McKenna met at Sydney's Gleebooks for an 'In-conversation' evening to discuss Nah Doongh's story and the historical thinking, sources and methods that made writing her story possible, as well as the wider implications of writing biographies of Aboriginal people. This is an edited transcript of their conversation.
\end{abstract}

Mark: We're here this evening to discuss Grace's recent essay 'Nah Doongh's Song', which has won the 2019 Australian Book Review's Calibre Prize. ${ }^{1}$ To my eyes it is nothing short of a masterclass in how to write history. So to begin, could you tell us a little bit about Nah Doongh? Why did you become interested in her?

1 Grace Karskens, 'Nah Doongh's Song', Australian Book Review, No. 413, August 2019, 31-37. www.australian bookreview.com.au/prizes-programs/calibre-prize/past-winners. 
Grace: Thanks very much Mark - and these are good questions! Nah Doongh was an Aboriginal woman, born about 1800 in the area around Penrith, on the Nepean River at the foot of the Blue Mountains. She died sometime in the late 1890s. She was about 3 or 4 years old when white people appeared in her country, and the thing that she talked about was how the settlers shot all the game - the soundtrack of invasion was gunfire. But Aboriginal people in this region were not instantly 'eliminated' by settlers. They were dispossessed of their richest lands, and it became more and more difficult for them to live in their Country, but they survived and they remained. So Nah Doongh was one of the first generation of Aboriginal people to grow up in a conquered land. She was of the same generation as other astonishing young people like Maria Lock, who became a matriarch and landowner, and Biraban, the stolen boy who grew up to become a Karadji - a doctor and clever man - and religious leader. These were resilient young people, and they had no choice but to find a way to survive in this unstable, dangerous post-invasion world. So, her story is about survival, but it's also about negotiating that world. How did she do it? How did she live? Where did she go?

I became fascinated by Nah Doongh's story while I was researching the history of the Hawkesbury-Nepean River for my next book. ${ }^{2}$ I'm interested in recovering the stories of marginalised people - the people left out of mainstream history. And there's a rich source of detailed information about Nah Doongh - which is very rare for a nineteenth-century Aboriginal person, let alone a woman. In 1886 Nah Doongh befriended a white woman named Sara Shand. Sara was a doctor's wife, a painter and a writer, who had just arrived from the north of England. She was very interested and curious to meet a 'real Aborigine', as she put it, and she asked Nah Doongh lots of questions, sketched and painted pictures of her. Nah Doongh often visited Sara, told her stories and even tried to teach her Aboriginal words. Eventually, during the 1891 flood, Nah Doongh moved in with the Shand family and looked after their children. Some years later, Sara wrote some detailed reminiscences about 'Black Nellie' - which is what the settlers called her - and they were published in the Nepean Times in $1914 .^{3}$

Mark: So her life spanned the entire nineteenth century?

Grace: Yes, the whole century: from Aboriginal Country to Federation; from the invasion to the railways. It's extraordinary to think that she saw all that unfold, and she was also part of it. 
Mark: I'd like to quote a few lines from the essay, which I think really go to the heart of what you're trying to do. Grace writes of how, in trying to track and comprehend Nah Doongh's life, she 'collided spectacularly with the methodological and ethical dilemmas at the heart of so much Aboriginal history', that is the fact that the richest records are usually created, of course, by the colonists. They come to us, you write, 'shaped by settler colonial ideas, about race and gender', and also as 'memorial archiving', the collection of Aboriginal artefacts, stories and images while Aboriginal people were still alive. Ironically, we know a lot about Nah Doongh because she's there in those European records. And you write very poetically that 'at every turn the evidence is profoundly mediated by happenstance, by vast silences and human figures are indistinct, they're like shapes deep under water, tiny clues flicker, their significance magnified by the unknowns'. You write that you bookend your essay with what you call 'ghost biography' and I'm really interested in getting you to say a little bit about what you understand by that term, 'ghost biography'.

Grace: Yes, it is so deeply ironic that the people and system which dispossessed and marginalised Aboriginal people also made the most detailed records about them - relatively speaking. Liz Conor's book Skin Deep: Settler Impressions of Aboriginal Women really lays out the extent and depth of racist ideas about Aboriginal women and especially old women like Nah Doongh. Liz Conor shows just how deeply ingrained and taken-for-granted these ideas were in settler society. ${ }^{4}$ So the sources are tainted; they are often repellent. But, like a number of Indigenous historians, I don't think we should reject these sources as evidence because of this. I believe the racist lens can be identified and called out; and what remains are precious records of people whose lives and presence would be lost otherwise. And we can contextualise them by gleaning meaning from across a range of other sources. We can go through lists, we can look at photographs and maps, we can read the body - we can turn those racist accounts on their heads and read them against the grain.

But, on the other hand, we have to have humility. I can argue a case, weave a story as far as the evidence goes but where it is insubstantial ghostly - I have to acknowledge that. This is the fallout of colonisation too, of course, the lack of proper records about Aboriginal people, because they were not considered important enough to record. I called the parts of the story about Nah Doongh's early womanhood, and about her death, 'ghost biography' because I can't say that I know what happened to her. 
Mark: So if it's ghost biography then it is, by nature, speculative. It has to step back from argument?

Grace: It has to step back from argument and be speculative, leave spaces and talk about the evidence: here is what we know; this is what it could mean. For example, we don't know for certain where and when Nah Doongh died. One source says she was buried at St Stephen's at Penrith, but she isn't listed on the burial register. I did find a burial record of an Aboriginal woman called Nellie, who died in the Newington Asylum in 1898 and was buried at Rookwood Cemetery. The certificate said she had 'no friends'. If this was Nah Doongh, the implications are awful - old and infirm, she was taken away from her Country and friends, and left in an alien place to die among strangers. But then, while some of the details fit, like the date, others don't: this woman couldn't speak English, for example, and we know Nah Doongh spoke English well.

Mark: You talk about the genre of biography, that it should, ideally, awaken us to the shared predicament of hidden and forgotten people. And also that biography is not a finite business, it's a process, it's a journey. I am wondering then, if the process has to be slow, by definition it takes years to do the digging that's required.

Grace: Yes - that's what I mean by slow history. I don't think you could write a respectful, truthful story about someone like Nah Doongh in, say 2 months with everything else that we do! I've been on her trail for a decade at least. This kind of work needs patience, minute detective work, lateral thinking and some serendipity - as well as consultation with Aboriginal people connected to her story. I can't help contrasting it with the way our universities are heading. We're bombarded with the language and values of business and industrial production, so somehow research is all about speed, productivity, efficiency, performance and annual quotas! It's another world from the kind of history that I want to write - I want to bring to people a new way of thinking about history, by writing new histories, forgotten histories, history from the ground up, the history that we need to know. This sort of work involves important questions, forensic research across lots of different disciplines and time to think and write. 
Mark: There's also the fact that we are still forced into old disciplinary categories - like the ARC (Australian Research Council), for example, where you can tick the box either for 'Aboriginal and Torres Strait Islander History' or 'Australian History' excluding Aboriginal and Torres Strait Islander History. This is quite remarkable given your work and the work of many other historians - those categories just don't make sense!

Grace: Yes. It's astonishing! Why are those categories still there? And in our leading research funding body? As though Indigenous history was not part of Australian history, as though settler and Indigenous histories were not entangled? It's a long time since we thought like that.

Mark: Can I take you to the sources in the essay? I really love the way you circle around your sources. A bit like a patient bird of prey in a way. You're eyeing, you're probing, testing, zeroing in, sorting half-truths from fiction, you're winnowing the text, as it were, chiselling away at the barest threads of evidence. You are reading the body, the landscape and art until Nah Doongh emerges more fully formed. I want to take you through how you actually used your sources. Let's start with Sara Shand's piece about Nah Doongh in the Nepean Times in 1914. You say this narrative is charmingly written but it has a lot of problems and obscures a lot of things, and also that you found a 'dark' version of her stories. I wonder if you could tell us a little bit about both these sources? But first, can you tell the story of how Nah Doongh arrives at the Shand house and Sara's reaction?

Grace: Oooh a patient bird of prey, I love that! Yes, it was a fascinating process of discovery! Sara wrote that Nah Doongh would always visit and then return to her little hut on the common. A lot of Aboriginal people lived on commons in this region - they were not private property and often they were still covered with bushland. But the 1890s saw another cycle of great floods on the Nepean. When they hit, Nah Doongh would stay with the Shands for a few days or a week and then she'd leave again. But the 1891 flood was massive, and Nah Doongh, who would have been in her early 90s by then, announced she was going to move in with them permanently. Sara didn't really believe it until she turned up at the house with a cart piled up with all her possessions, smiling cheerily and saying 'I've come to live with you!' And Sara writes, 'What could I do but welcome her?' [see Figure 2].

Mark: She moves in of her own accord. Wonderful!

5 '1297.0 - Australian and New Zealand Standard Research Classification (ANZSRC), 2008', Australian Bureau of Statistics, 31 March 2008, accessed 7 November 2019, www.abs.gov.au/Ausstats/abs@.nsf/Latestproducts/ E64DBD7D09B306A4CA2574180004C5A6?opendocument. 


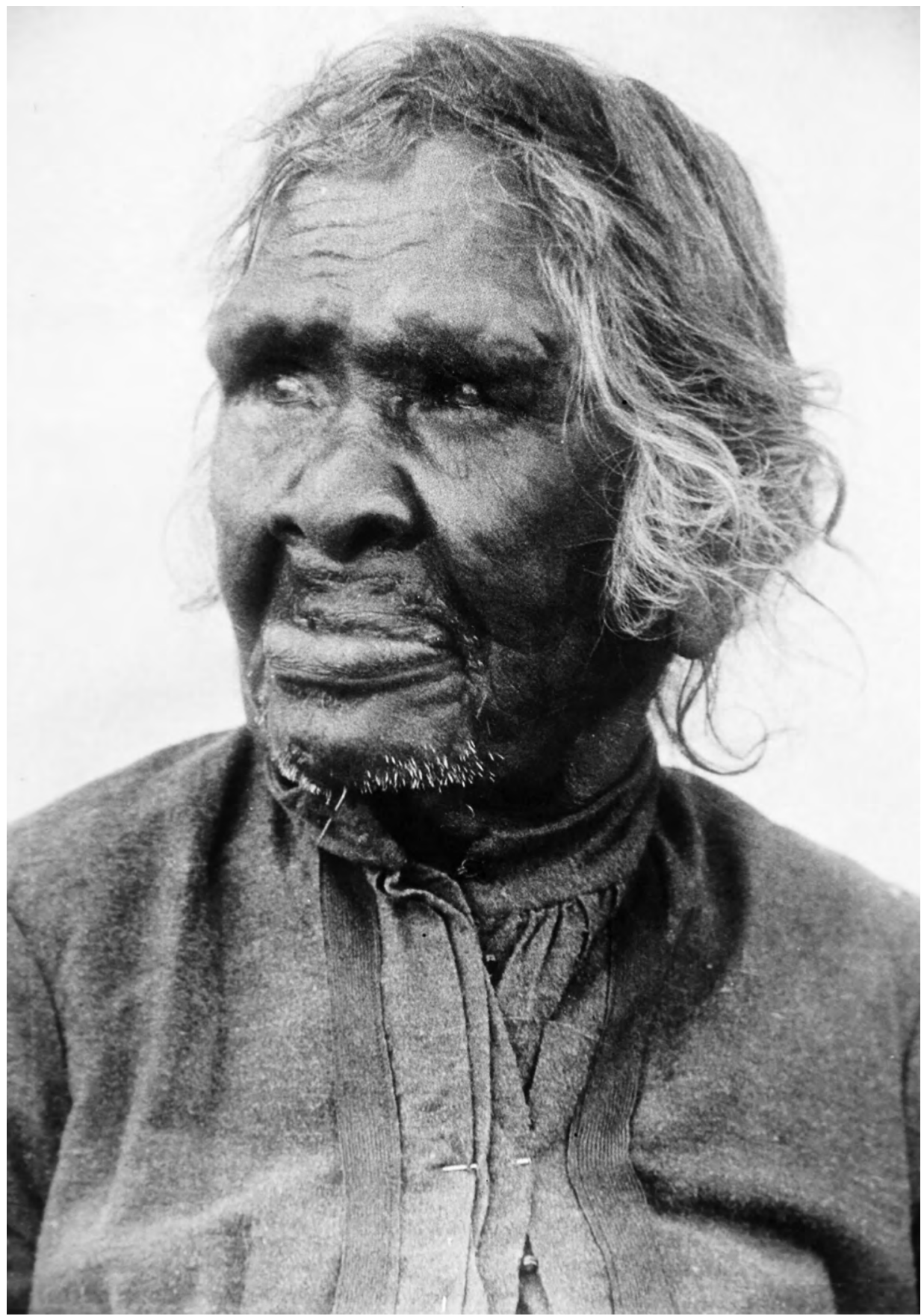

Figure 1: Nah Doongh in old age, Penrith, 1890s.

Source: Courtesy Penrith City Library, Local Studies Collection. 
Grace: Yes, it's her own decision - within the limits of her situation, she made decisions and took action. Sara wrote about it so humorously in the Nepean Times story in 1914. How she came to write the story is part of the bigger process of settler history-making - one of those times that Tom Griffiths calls 'high seasons of memory'. ${ }^{6}$ That year was the 100th anniversary of the building of Cox's Road over the Blue Mountains, and Penrith was celebrating big-time because the road and later the railway were the reason for its founding and growth. One way to mark the occasion - besides a big parade - was to publish the reminiscences of the oldest residents in the local newspaper. They were long, chatty stories, mostly about the pioneering days, bushrangers and Aboriginal people. By this time the Shand family had moved away from Penrith, though they kept in touch. My guess is that Sara read these pieces and was inspired to contribute her own - more elegantly written - stories about Nah Doongh, the 'last of her tribe', as she was known locally.

But I also discovered a 'dark' version of the story - or, that's how I think of it. It's in the Local Studies Collection at Penrith Library. This one was handwritten on lined paper, and I could see that it was George Bunyan's handwriting. He was an early local historian and collector. ${ }^{7}$ It's possible he asked Sara for more stories about Nah Doongh and wrote them out longhand. I call it a 'dark' version because it contains far more disturbing material than the published version. It reveals that Sara was quite cruel in the way she treated Nah Doongh, teasing and badgering her about sensitive subjects - her injuries for example, and about death - which Sara must have known was a taboo subject for Aboriginal people.

Mark: You write at one point, you're talking to yourself almost, I think, 'What if we placed Nah Doongh at the centre of her own story? What if we begin by listening closely to what she was trying to tell Sara Shand?' I'm really interested in this phrase, 'listening closely' if you can unpack that for me. Because it tells us a lot about how you're reading and interpreting the source, so, what does that process 'listening closely' mean? More precisely, how does it get transformed into historical narrative?

6 Griffiths, Hunters and Collectors, 197. See 'Reminiscences of Early Penrith', Nepean Times, 23 May 1914.

7 Sara Shand, 'Some Insights into the Character of Queen Nellie', c. 1914, transcript by George Bunyan, Local Studies Collection, Penrith City Library. 
Grace: Yes, good question. I would call it deep contextualisation. I've spent probably 10 or 15 years researching Aboriginal culture, the environment of the Nepean River, the society that grew up there after the invasion. This was how I began to make sense of what Nah Doongh was doing and saying. The irony is that, if I can borrow Paul Irish's book title, Nah Doongh's stories and words are 'hidden in plain view'. ${ }^{8}$ They've been published over and over again in local histories and heritage studies along with her photographs. Yet, no one asked: What does this actually mean? What is Nah Doongh telling Sara Shand? The way to unlock that is to take it bit by bit, to look very closely at what was she saying and doing, and contextualise the words and actions as deeply as possible, especially within Aboriginal understandings and spiritual beliefs. Then, slowly, these unfamiliar words and ideas start to speak.

Mark: You say that the most striking example of her voice was her song. Shand recalled that once a month she'd dress in her best clothes and go out. Occasionally returning drunk. There was a song that she sang:

All the Land Belonged to Mr McCarthy One Finger.

All the Land Belonged to Mr McCarthy Two Finger.

All the Land Belonged to Mr McCarthy Three Finger.

All the Land Belonged to Mr McCarthy Four Finger.

Grace: Yes, she counted her 4 fingers off as she sang that chorus. There were verses in Aboriginal language, but Shand didn't write them down, unfortunately.

Mark: So, let me ask you the question you ask yourself in the essay. What do we make of this song and how do you actually use that kind of process of slow, steady looking and excavation, to get at what she was singing. What does the song mean?

Grace: Well, first impression, 'all the land belonged to Mr McCarthy'. Obviously, the song is about a settler, who owns 'all the land', so it seems to be a song about possession and dispossession. There's one clue. But who was Mr McCarthy? Jim Kohen, an archaeologist who's done a lot of work in the region, had already suggested it was a local McCarthy family at Cranebrook, descended from an ex-convict called James McCarthy. ${ }^{9}$ They did own some land. But it didn't quite seem to fit, I mean, the gravitas of the song, the repetition, the counting off. Why would it be about them? It was only by a long and convoluted route that I discovered who she was singing about - and that she hadn't lived at Penrith all her life. 


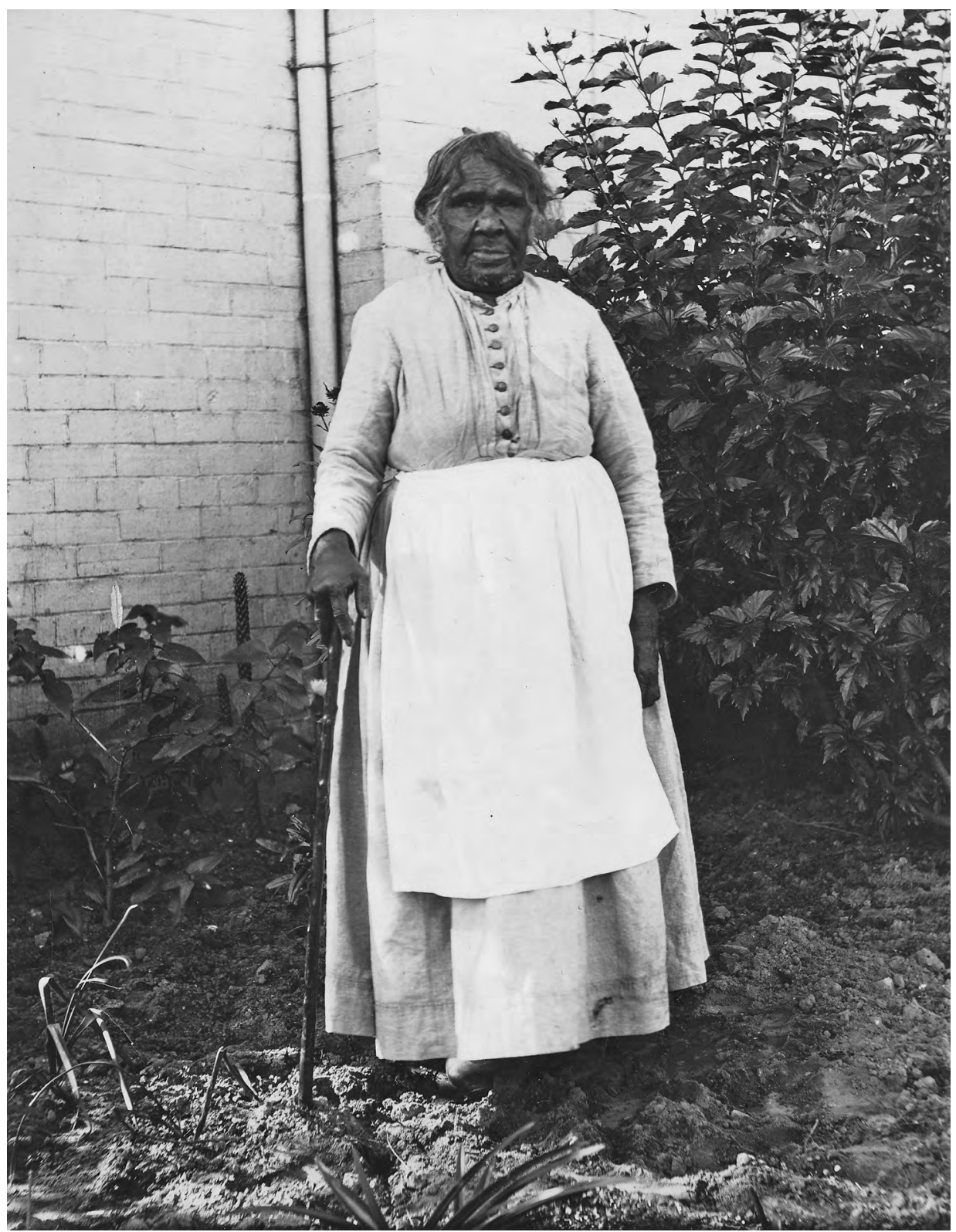

Figure 2: Nah Doongh, probably outside the Shand home in Penrith, c. 1891. Source: Courtesy Penrith City Library, Local Studies Collection. 
ABORIGINAL HISTORY VOL 432019

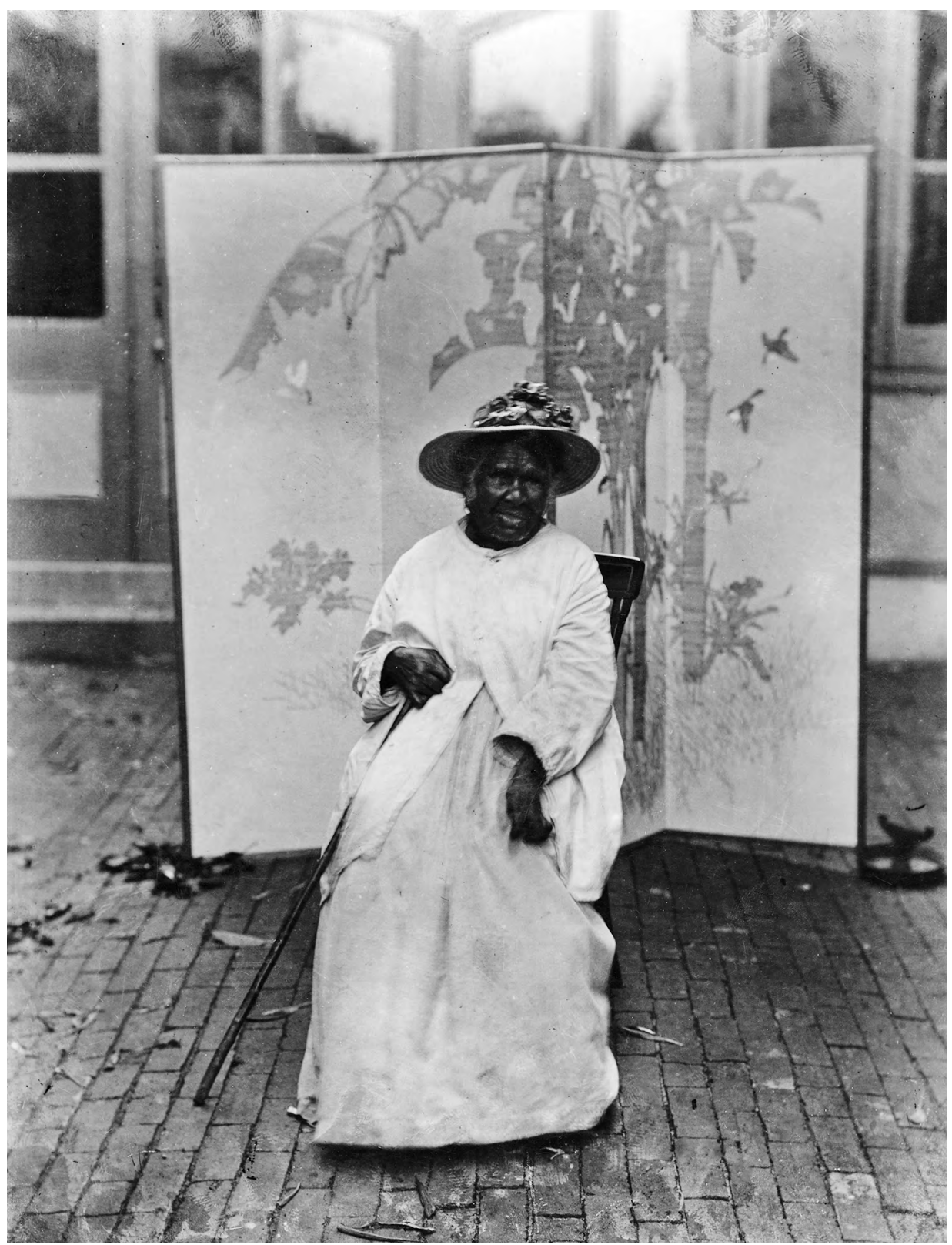

Figure 3: 'Black Nellie' outside the tile room at Camden.

Source: Courtesy Camden Historical Society. 
Grace: Lorraine Stacker, who is a historian and the local history librarian at Penrith, drew my attention to a photograph in the Camden Historical Society collection. It shows an Aboriginal woman called 'Black Nellie' in a white dress, seated outside the tile room at Camden, which is the estate of the Macarthur family [see Figure 3]. The Macarthurs were one of the most influential families in the colony. How do we know it's Nah Doongh? Because of her hand: it's misshapen, the same as in her Penrith photograph, and she's even holding the same walking stick. So then I wondered why Nah Doongh would be visiting Camden. I re-read Alan Atkinson's wonderful book Camden to see if he mentioned her. ${ }^{10} \mathrm{Well}$, it turns out that 'Black Nellie' - who was actually Nah Doongh - had married Johnny Budbury, a young Aboriginal man who lived on the estate. She may have lived at Camden for around 3 decades, a member of the larger Aboriginal group who lived on the Camden estate. However, Atkinson also says that Nah Doongh left Camden around 1865. She returned to her own Country at Penrith - Johnny followed her later. So, who is she singing about in the song? Most likely the wealthy, powerful Macarthurs. 'All the land belong to Mr McCarthy' rings true because, of course, they owned vast tracts of land. Also, there had been 4 generations of Macarthurs by this time, which possibly explains the 4 fingers in the refrain. The family was also important to Nah Doongh because she befriended the Macarthur women - just as she later befriended Sara Shand and other women around Penrith. It was one of her survival strategies.

Mark: So, it's a song about dispossession and loss of country.

Grace: Yes, I think so. I also think Aboriginal people were singing settler history to settlers. Shand was a newcomer, so Nah Doongh is singing to her, she's telling her what happened. We're finding more and more of these stories, and that in some places Aboriginal people were and remain the knowledge-holders for settler history, because they stayed with Country, while settlers often moved on. Samia Khatun's Australianama has some remarkable examples of this history-keeping and storytelling, and how that knowledge is being recovered. ${ }^{11}$

Mark: You also quote Nah Doongh talking about James Cook - Captain Cook. Can you tell us a little bit about that?

10 Atkinson, Camden, 207, 232.

11 Khatun, Australianama. 
Grace: Captain Cook, of course! This is the well-known post-contact Aboriginal mythology which Deborah Bird Rose and Maria Nugent have written about so well. ${ }^{12}$ Captain Cook is the mythological figure who strides across Country, taking land, bringing death and disease wherever he goes - he's the archetypal greedy, immoral settler. Aboriginal communities across Australia have different versions of the story. It's clear that it was already current in the nineteenth century because Nah Doongh knew the story too, and told it to Sara Shand in the 1880s or 1890s.

Why did she tell the Captain Cook story? Sara Shand, like a lot of settlers, was very interested in the first contact story - what was it like? What did you think of us when you first saw us? At first Nah Doongh tells her about Country - how it was still all forest, how the Aboriginal people far outnumbered the settlers. Which is historically correct - the invasion began slowly in this area. But then Sara Shand suddenly interrupts saying 'Poor Nellie, people taken all your country'. Nah Doongh does a doubletake, but then shoots back her own question: 'Well what did you come here for then? You're another white folk!' But remember, Sara is her friend, and she's living in her house, she is dependent on her. So she starts the story again, and this time it's the Captain Cook story, which is a way of deflecting the uncomfortable facts in this personal situation, but also of telling the larger truth. She said that Captain Cook was terrifying, a giant white man who came to Penrith with guns and shot all the game. In the end there was no game left for Aboriginal people and they all died, except for Nah Doongh.

Mark: It's a wonderful quote, and it brings us to landscape, which is itself an archive in all your work. I'm interested in how you track Nah Doongh and her movement across country and you talk about the work of Maria Nugent, Denis Byrne, Paul Irish (as you've done already) about life mapping or geo-biography. I'm wondering how you've applied those ideas to her life? And how you've tried to track her travels across the country? 
Grace: Sure, as Maria, Denis and Paul have written, geo-biography is a way of understanding past peoples or communities through their movements across Country - especially repeated movements, which trace out ongoing relationships between people and places. It reminds me powerfully of Rhys Isaac's simple but profound words about ethnographic history. He said that we need to watch people doing things, especially actions and movements that are repeated. ${ }^{13}$ Paul Irish mapped amazing patterns of continuity among the Aboriginal people of coastal Sydney, who were still moving up and down the coast in the twentieth century. This is so fascinating because it reveals those ongoing links, and it also helps us see past the idea that Aboriginal people were static, that they only moved around their own Country. They're constantly making long journeys for ceremonial or family business, so, not random journeys, but journeys with purpose and structure and proper protocols.

Nah Doongh moved a long way over her life too, and she returned to her own Country in her 60s. But her movements as a young woman are still uncertain - part of her ghost biography. It is possible that she went to the Liverpool area on the George's River to become the wife of the wellknown leader Coomun in the late 1810s. But the evidence is so slight - it's just 2 names - Nellie and Angelina. Coomun's wife was recorded as Nellie Colonga - clearly that's a very different name to Nah Doongh. Then again, Aboriginal people had many different names, including European nicknames. And Nah Doongh wasn't the only young Nepean woman to marry into the George's River group. There was also an alliance between the Nepean and Liverpool Aboriginal people in the early 1820s. So this move and marriage was not impossible.

The other name-clue is 'Angelina'. About the time Nah Doongh's husband died, a young girl named Angelina came to stay with her at Penrith. It's possible this was Angelina Timbery, the great-granddaughter of Coomun and Nellie Colonga. She was born in 1873, which makes her the right age for the girl who came to stay with Nah Doongh. It's a tantalising link, but was she really her great-granddaughter? So much hangs on this one name! Descendants of the Timbery family today say Nah Doongh is not related to them, and she herself never mentioned her family - in fact she said all her family had died.

13 Byrne and Nugent, Mapping Attachment; Irish, Hidden in Plain View; Isaac, The Transformation of Virginia. 
Mark: Let's come to the body now: the way that you read Nah Doongh's body. There's a photograph, of course, which you draw on, showing that her left hand is withered and that she holds a walking stick. You go to a specialist, Dr Stephen Oakley, who's a rheumatologist, show him the photograph and the evidence and ask him, 'Well can you help me with what this might mean?' and what does he tell you and why is it significant?

Grace: I was absolutely bowled over by this. I thought Stephen might be able to give me some information on how having a disability like that would affect Nah Doongh's daily life - to have one hand that's clawed and withered. He is interested in historical cases and he showed the images to 4 of his colleagues. They looked at the width of the wrist, the way the arm was hanging, the position. And to my amazement they came up with a diagnosis: Nah Doongh had Erb-Duchenne Palsy. This happens when the nerves in your arm are torn away from your neck. It means she wouldn't have been able to use that arm at all. She couldn't feel it, it would have been numb or tingling. So, she really only had the use of one arm. It is strange, because she was quite well-known in the area, yet no one ever mentions this disability, not even Sara Shand. One settler even remembered her as 'very muscular', as though she was big and strong. It's so odd!

Mark: To be honest, I can imagine a lot of historians, perhaps in the past, who would have just dropped the photograph in there but not thought to ask, 'Well could I actually find out the significance, what that actually means?' - and you've done that. It's another example of how you're reflecting on every last bit of evidence and getting the maximum amount you can from it.

Grace: It's precious!

Mark: The essay ends, with this wonderful clinching moment, which is quite extraordinary. You find an image online of Sara Shand's portrait of Nah Doongh ... so tell us about that moment of discovery. 


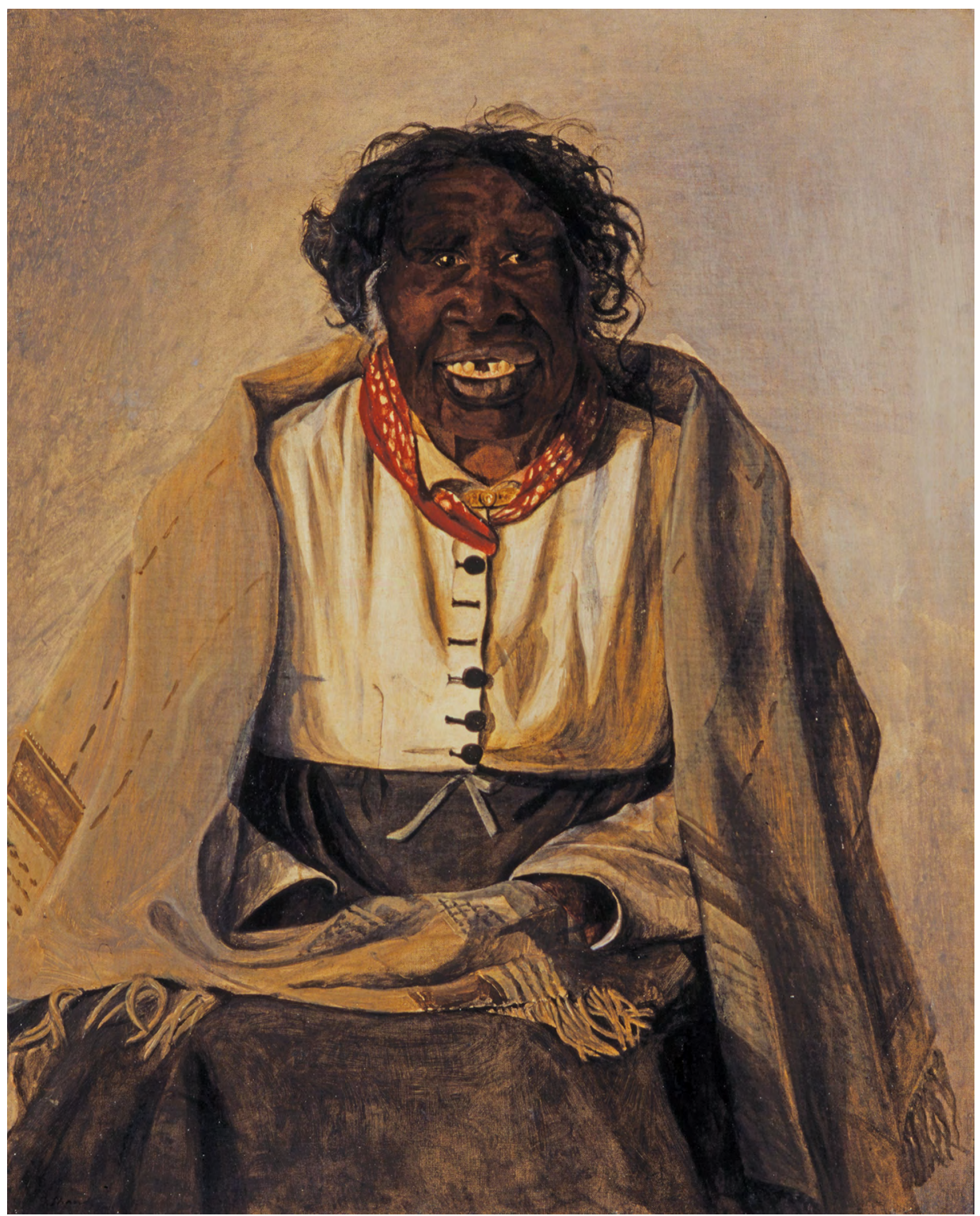

Figure 4: Portrait of Nah Doongh by Sara Shand, 'Nellie the Cook'. Source: Private collection. 
Grace: That painting haunted me for years! Sara Shand wrote that she painted a portrait of Nah Doongh, and it was quite well-known locally, hung in local shows, mentioned in the newspapers. I always wondered what happened to it. I tracked down a reference that it was hanging in the Penrith School of Arts until the mid-1950s, but then disappeared. I know how easily things like that can be thrown out, sent to the tip, but I kept thinking, what if it is still around, stashed in an attic somewhere? After I'd done most of the research, I Googled it one more time - 'Sara Shand Nellie painting'. I wasn't expecting anything at all, but there was a hit! My internet speed was very slow at the time and it took forever but slowly this painting appeared on my screen, and it was her! I was so shocked and so delighted. There she was grinning good naturedly, wearing the same dress she's wearing in the photograph, with a faded shawl around her shoulders - the shawl was a gift from the Macarthur women [see Figure 4]. The painting was spotted at auction by an art restorer who cleaned and restored it - and then it was sold to a private collector, who unfortunately took it overseas. ${ }^{14}$

Mark: One of the great things about your essay is its ability to be comfortable as speculative history, as ghost biography, I guess, but it's not fictional and I'm interested in asking you if you could ever imagine wanting to fill in the gaps, using your own imagination and, of course, historical knowledge, and writing not a ghost biography but a fictional biography? And if not, why not?

Grace: Such an interesting question! My first response is: no, I don't think I could write a completely fictionalised story to fill in the gaps. Then again, where are the boundaries between history and fiction? I often reimagine historical vignettes, or people doing things - like the picture of Nah Doongh on the train to Camden to visit old friends, sitting on the dark leather seats in her dress and 7 petticoats. But all this comes out of research. I know Nah Doongh did travel there by train, I know how she dressed and what the train seats looked like at that time. Am I writing fiction? Or using 'historical imagination', as Greg Dening called it. But when the evidence gets too thin and there are gaps in historical records I speculate from what we do know: this is probably what happened, or this is the most likely explanation; and I reveal the evidence that is available - bringing readers into a historical question, but also making them aware of these silences, which are part of the story too.

14 Duncan Hulme, personal communication, June 2017, and Peter Lane, October 2018. 
Mark: Yes, I think it depends on the reader too, of course it always does, but when I was reading your essay, I really liked the fact that there were lots of spaces in there. You lay the evidence out, you give us everything we could possibly need to make our own interpretation. It's the best way to approach this kind of biography. There's space there for the reader to do that. I don't want you, Grace Karskens, to say, 'Well this was this, it was ABCD'. I don't want you to do that.

Grace: I agree. I think it's important to acknowledge these ambiguities, and to let the readers know what we do. Like, how do we sort these things out? How do we decide whether she went to Liverpool or not? In this case we can't, but we can say why it might be possible or likely that she did.

Mark: I thought I'd like to ask you a general question about the arc of your work. As a historian, you've in a way circled what you call Sydney's sandstone arc. You've been in Western Sydney, Prospect, you've been in The Rocks, of course, in Sydney itself, the Cumberland Plain, The Colony and, any minute now, the Hawkesbury-Nepean. So, there's this arc, but are you going to head south?

Grace: Well, I still find the Sydney region endlessly fascinating - it's so diverse in landscapes, ecologies, people. So many multi-layered stories still to be told! So many mysteries! It has one of the longest Aboriginal histories in Australia, yet it's also the site of the biggest city in Australia. Lately I have been thinking more broadly about the larger region, the 'sandstone circle', the vast area of sandstone country that reaches from say, Wollongong, around to the west escarpment of the Blue Mountains and the Wollemi and then north and east, almost to the Hunter Valley to the north and east. Aboriginal art and sacred and ceremonial sites are linked right across this region - it has its own distinctive regional style. So I thought, imagine working at this scale! Not just the coast or the river, but this whole inspirited region. There has been so much work done across the region by all sorts of researchers and writers in history, archaeology, ecology, geology and so on. There are numerous Aboriginal communities and organisations. What if we could pull it all together?

Mark: In terms of the future, after this book that's coming out very shortly, do you have an idea of where you want to go? 
Grace: Right now it is hard to see past People of the River, which will be a kind of companion volume to The Colony, but looking at the first settler farming frontier on the Hawkesbury-Nepean River - so it's about the rural origins of modern Australia and how that was entangled with Aboriginal history and culture. I'm also working on an exciting project with a team of Darug researchers called 'The Real Secret River: Dyarubbin'. It's based around a list of Aboriginal names for the Hawkesbury and Macdonald rivers that I came across in the library a couple of years ago. That was a shock because I thought the Aboriginal names were lost forever, yet, here's this list of 178 Aboriginal names, including the names of Windsor, Richmond, the Blue Mountains! What we're doing is relocating and mapping as many as we can, doing fieldwork and recording Aboriginal memory and knowledge. We're working with linguist Jim Wafer on glossing the words, and also with archaeologist Paul Irish so we can map the archaeological sites on the river. We're taking a whole-of-Country approach. Some of the findings are truly amazing. We may be able to map an Aboriginal geography of the river in the 1820s, both the natural environment and the sacred landscape.

So now I'm wondering whether 'The Real Secret River: Dyarubbin' project could be a kind of pilot study for a larger regional project - the sandstone circle. I am inspired by what Megan Davis has to say about regional histories, which can be told around landscapes and places. Regional and local histories can be intimate, as you yourself have shown so brilliantly Mark. ${ }^{15}$ This is the scale that really speaks to people because it explores, gives deeper meaning to the familiar and everyday. Megan Davis went on to say that the truth about massacres and frontier war has to be told in these histories, but other stories and places could be there too - like the social and ceremonial grounds, and places where Aboriginal people and settlers maintained friendships. She sees these histories as the essential first step towards Makarrata - reconciliation after a period of conflict because there can't be reconciliation before a truthful history has been understood and acknowledged. ${ }^{16}$

Mark: You've just reminded me, there's one more question I'd like to ask. When you're looking closely for Nah Doongh's voice, are there ethical dilemmas in finding it? Is there an edge to that process?

15 McKenna, Looking for Blackfellas' Point.

16 Davis, 'From the Expert Panel to the Referendum Council'. 
Grace: Yes, there are ethical dilemmas, as there are in any research involving Aboriginal people - starting with the racism embedded in many of the sources I mentioned earlier. I think it's now widely known and accepted that we must decolonise Australian history, but this also means decolonising how we do history. I am a non-Indigenous person; my parents were migrants from the Netherlands and Indonesia. I am committed to researching and writing colonial history as fully as I can and this means taking Aboriginal and cross-cultural history as seriously as settler history, whatever challenges that may involve. I try to involve Aboriginal people as fully as possible in the research and the writing and acknowledge their contributions. Consulting Aboriginal people for their perspectives is especially important. For 'Nah Doongh's Song' I talked to Michael Ingrey, a Gadhungal man from La Perouse, who knows her story and can speak for the La Perouse people. By an amazing historical twist, Michael is also descended from Sara Shand! So he knows stories about her that were passed down the Shand family. Nah Doongh herself doesn't appear to have descendants, or none who recognise her. This is part of her story. She didn't mention any children, and after her husband died she didn't have anyone besides her white friends when she got old. There were other Aboriginal groups in the region - the people up at Katoomba, down at Burragorang, on the Hawkesbury at Sackville and at the old Blacktown camp on the Richmond Road. But they weren't her people and she didn't like them.

Mark: Thanks so much, Grace. It's incredible really because this is a 5,000-word essay and just look at how much work has gone into this, how much time, and what a lesson it is. It's a really inspiring piece of work.

Grace: Thank you Mark!

\section{References}

Atkinson, Alan. Camden: Farm and Village Life in Early New South Wales. Melbourne: Oxford University Press, 1988.

Byrne, Denis and Maria Nugent. Mapping Attachment: A Spatial Approach to Aboriginal Post-contact Heritage. Sydney: Department of Environment and Conservation, 2004.

Conor, Liz. Skin Deep: Settler Impressions of Aboriginal Women. Perth: University of Western Australia Press, 2016.

Davis, Megan. 'From the Expert Panel to the Referendum Council: The Role of Truth and Justice in Constitutional Reform'. Practical Justice Initiative Indigenous Lecture Series, UNSW, September 2017.

Griffiths, Tom. Hunters and Collectors: The Antiquarian Imagination in Australia. Melbourne: Cambridge University Press, 1996. 
Irish, Paul. Hidden in Plain View: The Aboriginal People of Coastal Sydney. Sydney: NewSouth Books, 2017.

Isaac, Rhys. The Transformation of Virginia 1740-1790. Chapel Hill, NC: University of North Carolina Press, 1982.

Karskens, Grace. 'Nah Doongh's Song'. Australian Book Review, No. 413, August 2019, 31-37.

Karskens, Grace. People of the River: Lost Worlds of Early Australia. Sydney: Allen \& Unwin, 2020.

Khatun, Samia. Australianama: The South Asian Odyssey in Australia. St Lucia, Qld: University of Queensland Press, 2019. doi.org/10.1093/oso/9780190922603.001.0001.

Kohen, James. The Darug and Their Neighbours: The Traditional Aboriginal Owners of the Sydney Region. Sydney: Darug Link and Blacktown and District Historical Society, 1993.

McKenna, Mark. Looking for Blackfellas' Point: An Australian History of Place. Sydney: UNSW Press, 2002.

Nugent, Maria. Captain Cook Was Here. Melbourne: Cambridge University Press, 2009.

Rose, Deborah Bird. Dingo Makes Us Human: Life and Land in Australian Aboriginal Culture. Cambridge: Cambridge University Press, 2000.

Shand, Sara. 'Some Insights into the Character of Queen Nellie', c. 1914. Transcript by George Bunyan. Local Studies Collection, Penrith City Library. 
This text is taken from Aboriginal History, Volume 43, 2019, edited by Ingereth Macfarlane, published 2020 by ANU Press, The Australian National University, Canberra, Australia.

doi.org/10.22459/AH.43.2019.03 